\title{
Design and Practical Investigation of a Model Predictive Control for Power Grid Converter
}

\author{
Abderrahmane Berkani ${ }^{1 *}$, Karim Negadi ${ }^{1},{\text { Ahmed } \mathrm{Safa}^{2}, \text { Fabrizio Marignetti }}^{3}$ \\ ${ }^{1}$ Laboratory of L2GEGI, Department of Electrical Engineering, Faculty of Sciences Applied, University of Tiaret, Algeria \\ ${ }^{2}$ Laboratory of Electrical Engineering and Plasmas, Faculty of Sciences Applied, University of Tiaret, Algeria \\ ${ }^{3}$ Dipartimento di IngegneriaElettrica e de ll'InformazioneUniversitàdegliStudi di Cassino e delLazioMeridionale, Cassino, Italy
}

Corresponding Author Email: abderrahmane.berkani@univ-tiaret.dz

https://doi.org/10.18280/ti-ijes.642-434

Received: 20 March 2020

Accepted: 4 June 2020

\section{Keywords:}

model predictive control, current control, twolevel inverter, power grid, $D C$ to $A C$ power convertor, Dspace 1104

\begin{abstract}
This paper presents a Model Predictive Power Control (MPC) scheme for the control of three-phase grid-connected with two Level Voltage Source Converters (2 LVSCs). This work utilizes the discrete behavior of the converter to determine appropriate and optimal switching states that minimize the cost function. The proposed approach based predictive control scheme allows power transfer with instantaneous mode changing capability and fast dynamic response. For both operation modes, the simulation and experimental results confirm the good performance in terms of efficiency, low current THD and controlled output voltage.
\end{abstract}

\section{INTRODUCTION}

In recent years power electronic converters play a major role in the grid integration of renewable energy systems [1]. These converters are used to regulate and shape an electrical signal in the required form. Among these converters, AC-DC converters, commonly known as rectifiers, are used extensively in renewable energy systems such as gridconnected DC microgrids, grid-connected solar photovoltaic energy conversion systems, etc. [2, 3].

Model Predictive Control (MPC), which was developed in the process control industry in the 1970's, has received significant attention from industry and academia due to its fast dynamic response, conceptual simplicity and the ability to include nonlinearities and constraints in the design of the controller [1].

Several MPC-based strategies have been proposed for gridconnected converters, with a number of these directly regulating the active and reactive powerdelivered to (or drawn from) the grid by selecting the switching state of the converter.

DPC selects an optimal converter state in a similar manner to DTC by utilizing a switching table and hysteresis bounds. The Virtual Flux (VF) technique was first proposed for DPC. The VF technique makes the assumption that the grid voltage and AC- side resistance and inductance are quantities which can be related to an AC machine. The use of VF vectors in DPC enables the elimination of grid voltage sensors and a simple power calculation [4].

In the same way that MPDTC extends on DTC, Model Predictive Direct Power Control (MPDPC) can be viewed as an extension of DPC, replacing the switching table with an online optimization stage. This paper presents a VF-based MPDPC scheme for three-phase grid-connected VSCs. Under steady-state conditions, the key performance indicators are the converter switching losses, $\mathrm{P}$ sw, and the Total Demand Distortion (TDD) of the grid current, TDD. Under transient conditions performance is judged by the response time of the output following reference steps. In order to benchmark the performance of MPDPC, it has been compared against Pulse Width Modulation (PWM) and Optimized Pulse Patterns (OPP). The different schemes have been compared through simulation of a three-level, three-phase Neutral Point Clamped (NPC) converter.

This paper presents Model Predictive Direct Power Control (MPDPC), a new approach to the control of grid-connected converters, which regulates the instantaneous avtive and reactive power delivered to the grid within a set of symmetrical bounds, whilst minimising the device switching frequency of the converter.

This article is organized as follows: in section 2, the description of the proposed circuit is defined, this section display the physical modeling of different part with their equations model. Control strategy applied to the whole system with their step and equations model are shown in section 3 . In section 4, we validated the theoretical study part and the proposed control algorithms and a dynamic model of the system is modeled and simulated in Matlab/Simulink. The description of the setup bench is detailled in section 5. Section 6 , shown the obtained experimantal result tested on the platform board. Finally, conclusions are drawn in section 7.

\section{THREE PHASE TWO LEVEL INVERTER AND ELECTRICAL POWER GRID MODOLLING}

Figure 1 shows the power circuit of grid-connected to two levels voltage source converter.

The active power is considered to flow from the DC circuit to the utility grid. The phase-leg of grid connected consists of two switches based on insulated-gate bipolar transistors (IGBTs).

The active power extracted by the renewable energy sources is represented by a variable DC current source, $i_{d c}[5]$. 


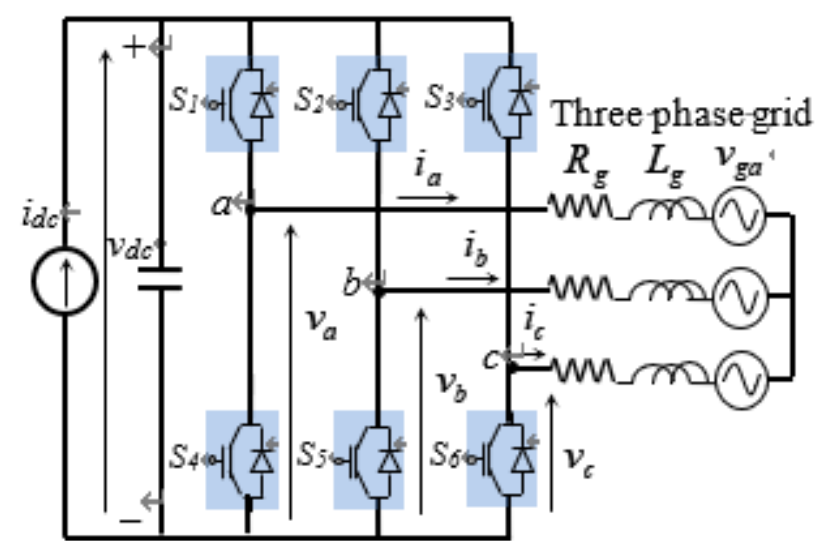

Figure 1. Schematic of two-level voltage source inverter topology

The dynamic model of the grid connection in reference frame rotating synchronously with the grid voltage is given as follows:

$$
\left\{\begin{array}{l}
v_{d g}=v_{i d}-R_{g} i_{d g}-L_{d g} \frac{d i_{g d}}{d t}+L_{q g} \omega_{g} i_{q g} \\
v_{q g}=v_{i q}-R_{g} i_{q g}-L_{q g} \frac{d i_{q d}}{d t}-L_{d g} \omega_{g} i_{d g}
\end{array}\right.
$$

The DC-link system equation can be given by:

$$
C \frac{d v_{d c}}{d t}=\frac{3 v_{d g}}{2 v_{d c}} i_{d g}-i_{d c}
$$

where, $v_{d g}, v_{q g}$ are the direct and quadrature components of the grid voltages, $v_{i d}, v_{i q}(\mathrm{~V})$ are the inverter voltages components, $R_{g}, L_{d g}, L_{q g}$ are the resistance, the direct and quadrature grid inductance, respectively, $i_{d g}, i_{q g}$ (A) are the direct and quadrature components of the grid currents, respectively, $v_{d c}$ is the DC-link voltage, $i_{d c}$ is the grid side transmission line current and $\mathrm{C}$ is the DC-link capacitor.

The power equations in the synchronous reference frame are given by [6]:

$$
\left\{\begin{array}{l}
P_{g}=\frac{3}{2}\left(v_{d g} i_{d g}+v_{q g} i_{q g}\right) \\
Q_{g}=\frac{3}{2}\left(v_{d g} i_{d g}-v_{q g} i_{q g}\right)
\end{array}\right.
$$

After orienting the reference frame along the grid voltage, $v_{q g}$ equals to zero by aligning the d-axis. Then, the active and reactive power can be obtained in this new reference from the following equations:

$$
\left\{\begin{array}{l}
P_{g}=\frac{3}{2} v_{d g} i_{d g} \\
Q_{g}=\frac{3}{2} v_{d g} i_{q g}
\end{array}\right.
$$

\section{PROPOSED MODEL PREDICTIVE CONTROL METHOD}

Three-phase two level grid connected VSI is a very wellknown topology in power electronics. Simplified circuit diagram of the system has been illustrated in Figure 1. It has been composed of six IGBT modules and connected to the filter inductor, resistor, and grid voltage. The mathematical equation of the system model can be described by the space vector analysis as follows [7]:

$$
v=L_{g} \frac{d i}{d t}+R_{g} i+v_{g}
$$

where, $\mathrm{v}, \mathrm{i}$ and $\mathrm{e}$ are the representations of the inverter voltage vector, grid current vector and grid voltage vector, respectively; $\mathrm{R}$ and $\mathrm{L}$ are the filer resistance and filter inductance.

$$
i_{g}(k+1)=\left(1-\frac{R_{g} T_{s}}{L_{g}}\right) i(k)+\frac{T_{s}}{L_{g}}\left(v(k)-v_{g}(k)\right)
$$

Since the MPC method is based on the discrete-time equation, the system model should be discretized with sampling period $(T s)$ in order to predict the future value. By using the forward Euler method on (1), the discrete-time model of the system will be expressed as follows:

$$
g=i_{g}^{*}(k+1)-i_{g}^{p}(k+1)
$$

where,

$k$ is the presentation of the instant that the last switching state has been applied to the inverter and $k+1$ represents the next sampling instant, $i(k)$ and $v_{g}(k)$ is measured from the hardware sensors and $v(k)$ can be obtained by using switching state of the inverter. Considering all the possible combinations of the switching state, eight voltage vectors $\left(\mathrm{V}_{0} \sim \mathrm{V}_{7}\right)$ are obtained as shown in Figure 2(a). Therefore, the eight future grid current vectors $i_{0}(k+1) \sim i_{7}(k+1)$ are predicted from (2). To determine the optimum voltage vector among the possible voltage vectors $v_{0}(\mathrm{k}) \sim v_{7}(\mathrm{k})$, the cost function is defined asfollows [8]

\subsection{Measured voltages and current}

The measured three-phase grid voltages and currents, and DC link voltage $v_{d c}$ are supplied as input signals to the control scheme [9]. The PCC scheme generates switching signals $S_{a i}, S_{b i}$, and $S_{c i}$ for the GCC. For a balanced threephasegrid, it is not necessary to measure phase-c grid voltages and currents because:

$$
\begin{gathered}
v_{c g}(k)=-v_{a g}(k)-v_{b g}(k) \\
i_{c g}(k)=-i_{a g}(k)-i_{b g}(k)
\end{gathered}
$$

The control algorithm of the conventional MPC method can be described to the following steps [10];

1. Applying the switching state $\mathrm{S}(\mathrm{k})$

2. Measure the $\mathrm{i}(\mathrm{k})$ and $\mathrm{e}(\mathrm{k})$ 
3. Predict the $\mathrm{i}(\mathrm{k}+1)$ for all the possible switching states.

4. Calculate the cost function with the $i^{*}(k+1)$ and $i(k+1)$

5. Determine the optimum voltage vector

6. Store switching state according to the optimum voltage vector

\subsection{Prediction step}

From $i(k+1)$ on the controller can use any possible output to bring the controlled currents that closer to their reference. In the next step $i(k+2)$, the prediction step, the controller thus calculates the measured currents at $k+2$ for all possible switch states at $k+1$. With long prediction horizon ( $n$ steps) the output current with RL-Load can be expressed as [11]:

$$
\begin{aligned}
{\left[\begin{array}{c}
i_{d}(k+n) \\
i_{q}(k+n)
\end{array}\right]=} & {\left[\begin{array}{rc}
1-T_{s} \frac{R_{g}}{L_{g}} & 0 \\
0 & 1-T_{s} \frac{R_{g}}{L_{g}}
\end{array}\right]\left[\begin{array}{l}
i_{d}(k+n-1) \\
i_{q}(k+n-1
\end{array}\right] } \\
& +\left[\begin{array}{cc}
\frac{T_{s}}{L_{g}} & 0 \\
0 & \frac{T_{s}}{L_{g}}
\end{array}\right]\left[\begin{array}{c}
v_{d}(k+n-1) \\
v_{q}(k+n-1)
\end{array}\right]
\end{aligned}
$$

\subsection{Cost Minimization Function}

The main objective of the model predictive control algorithm is to minimize the error with fast dynamic response between the predicted and reference values of the discrete variables. In order to achieve this objective, an appropriate cost function e is defined with the reference and predicted value of current vector [12]. Hence, the cost function for the rectifier and inverter can be expressed with the absolute error between the predictive and reference values of input and load current for the rectifier and inverter modes as:

$$
g=\left|i_{r e f}(k+1)-i_{p}(k+1)\right|
$$

where, $g$ is the cost function. The reference input and predicted current are $i_{\text {ref }}(k+1)$ and $i_{p}(k+1)$.

\subsection{Proposed control schema}

The power control block diagram in $d q$-frame for a gridconnected two-level voltage source converter (2L-VSC) is shown in Figure 2. The 2Level VSC control system performs the following functions: grid active power control through the d-axis current control, grid reactive power control through the $q$-axis current control, and grid synchronization [13].

\section{SIMULATION RESULTS AND DISCUSSIONS}

Simulations were carried out under the MATLAB/Simulink platform for a 2L VSC with control schema shown in Figure 3 , considering the electrical parameters that are shown in Table 1 .

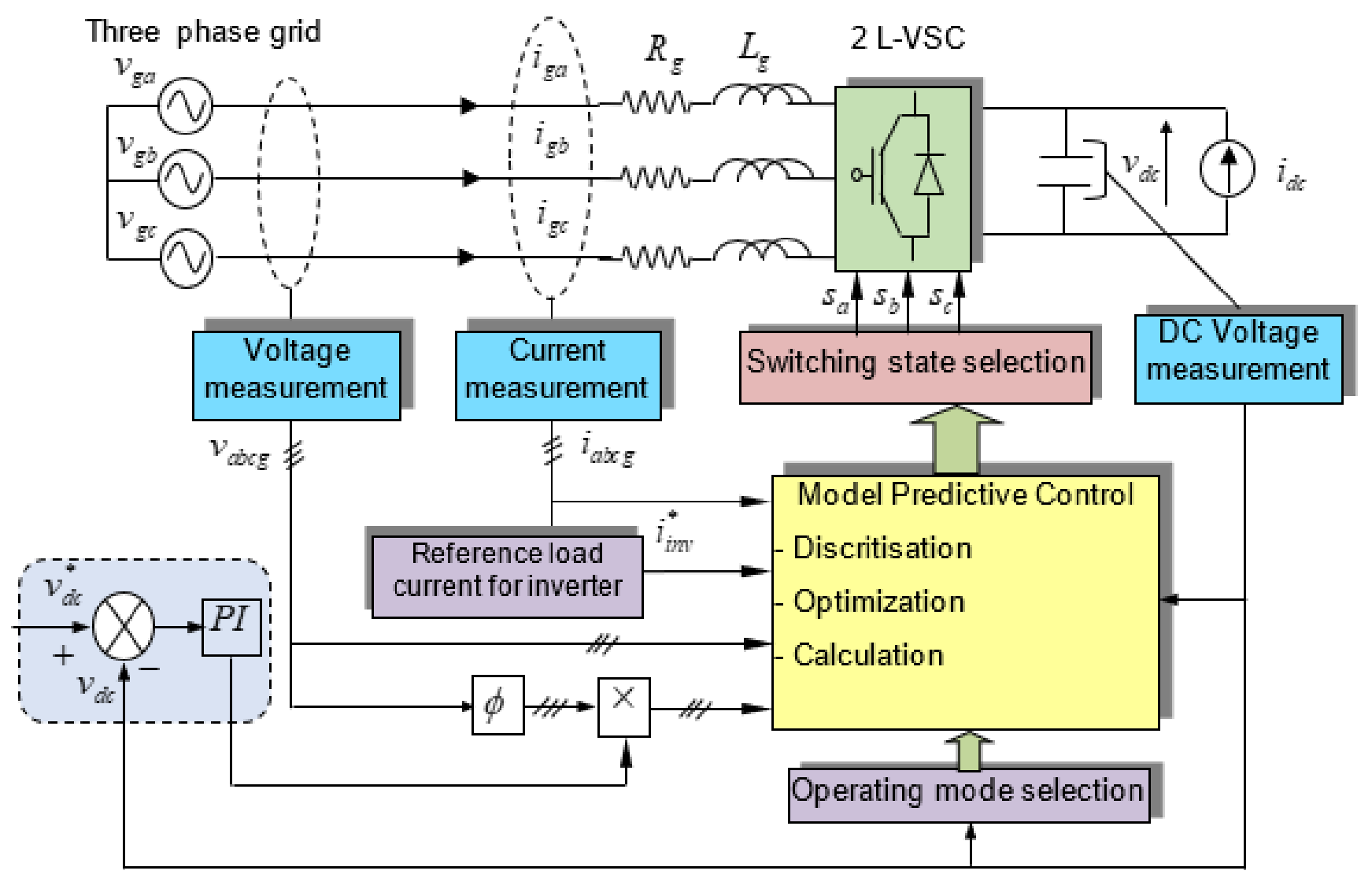

Figure 2. Proposed MPC control shceme 


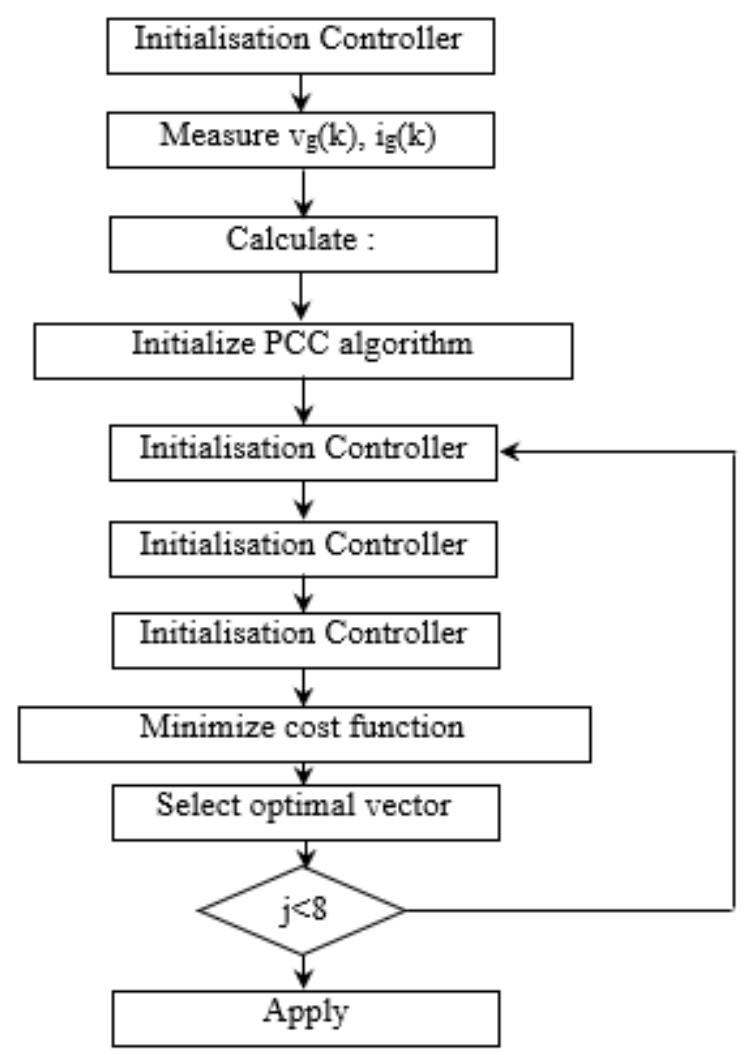

Figure 3. Steps of the applied PCC algorithm
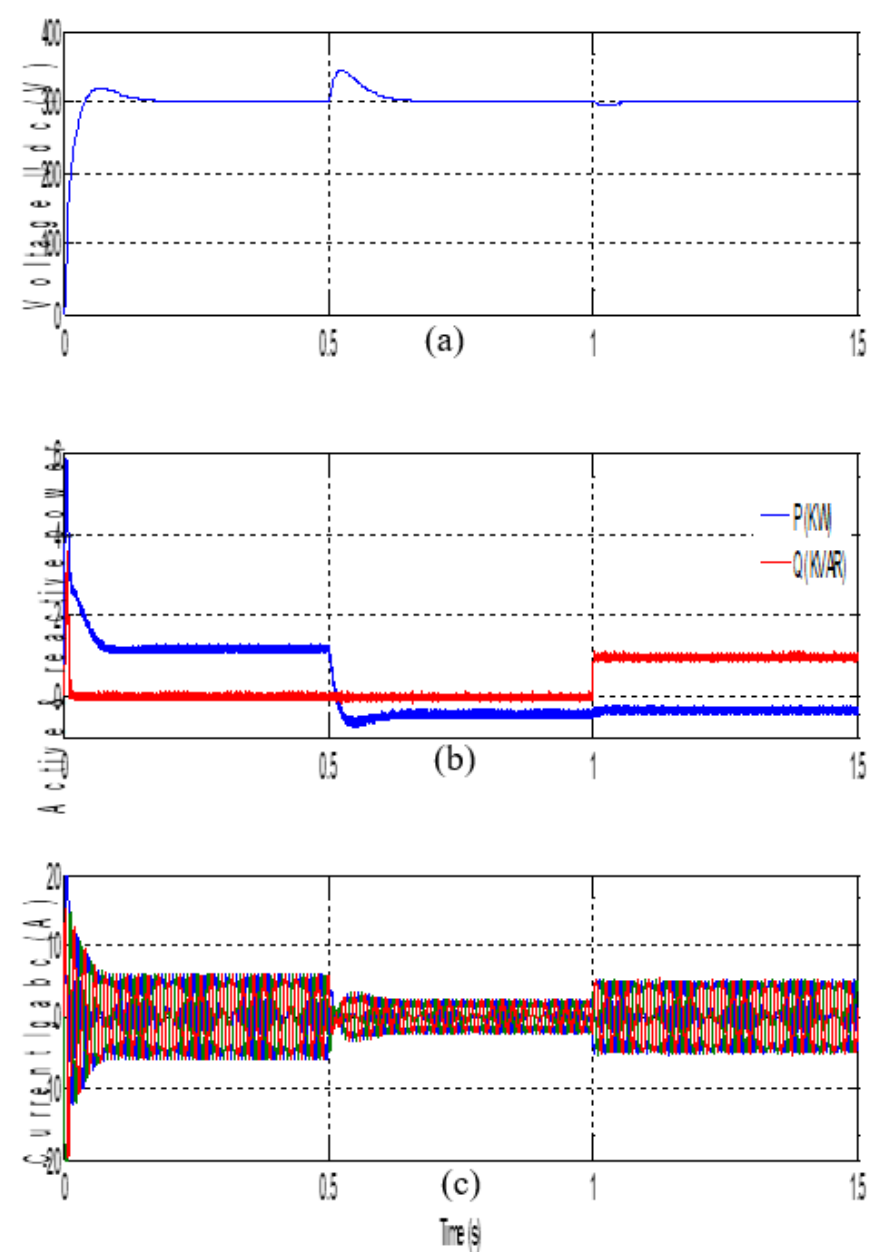

Figure 4. Tracking performance of proposed control: dc voltage, active and reactive powers and output currents
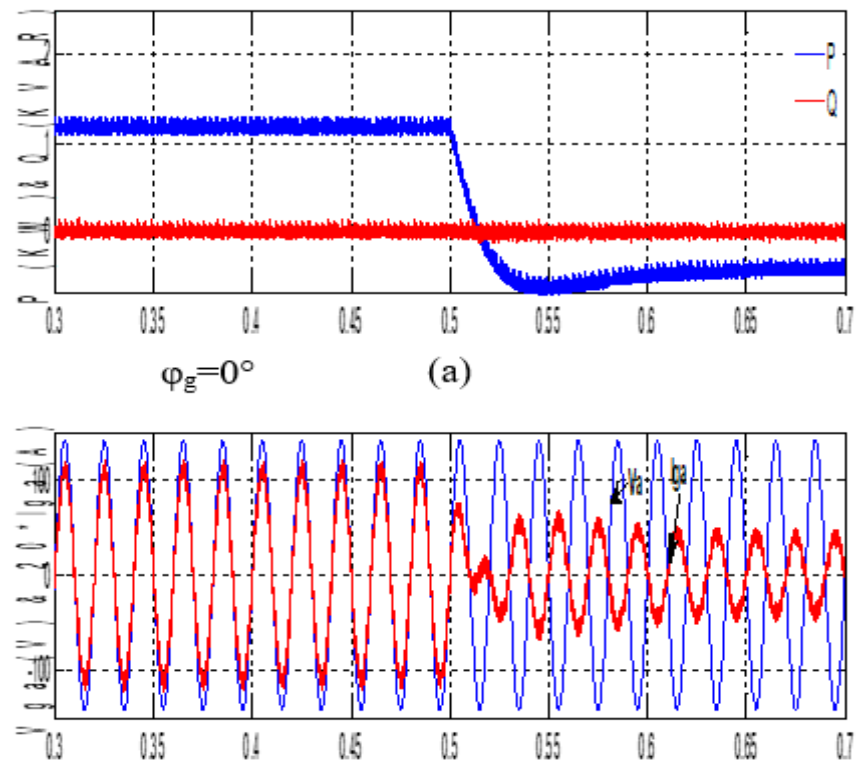

(b)

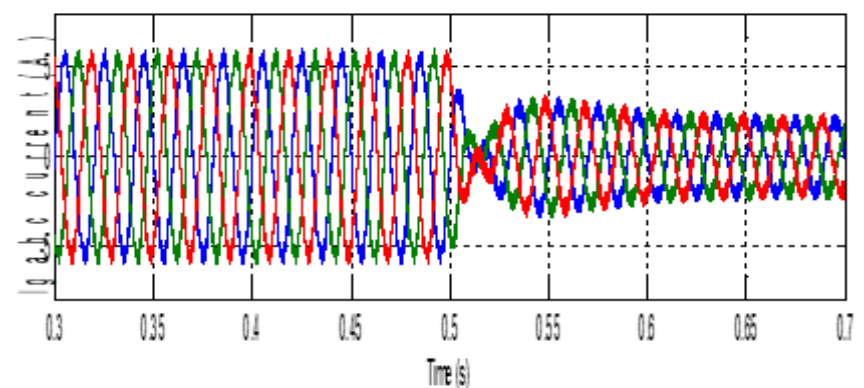

(c)

Figure 5. Tracking performance of the proposed control strategy: active and reactive powers, voltage vga and current iga, output currents

The dynamic behavior under dc current $\mathrm{i}_{\mathrm{dc}}$ variation at $\mathrm{t}=0.5$ $\mathrm{s}$ and reactive power variation at $\mathrm{t}=1 \mathrm{~s}$.

It shows the waveforms of the active and the reactive power, the grid phase a voltage and current and the three phase grid current respectively.

The Figure 6 (b) show the grid phase a voltage and current, we notice that these quantities are $180^{\circ}$ degree phase shift which means the reactive power equal to zero.

The introduction of the P-DPC control, resulting from the minimization of the cost function, made it possible to obtain the lowest THD and yielded a faster dynamic response with a steady state which presents a better power ripple.

One important performance measure of a converter system is the voltage of DC-link between the input reference side converter and the grid-side converter, as shown is Figure 4 (a). The DC voltage remains outstandingly insensible to the variation of the active and reactive power reference flow with smaller ripple.

Figure 4 (b) show the variations of active and reactive power, the active power keeps its nominal value of $1.5 \mathrm{KW}$ and the reactive power remains near zero and change at $t=1 \mathrm{~s}$ at $1 \mathrm{KVAR}$

The three phase current grid is display on Figure 5 (c), they are purely sinusoidal with a variation at time $\mathrm{t}=0.5 \mathrm{~s}$ and $\mathrm{t}=1$ $\mathrm{s}$ respectively due to variations in the references. It is also noted that the three-phase currents obtained have less oscillation and chattering. 

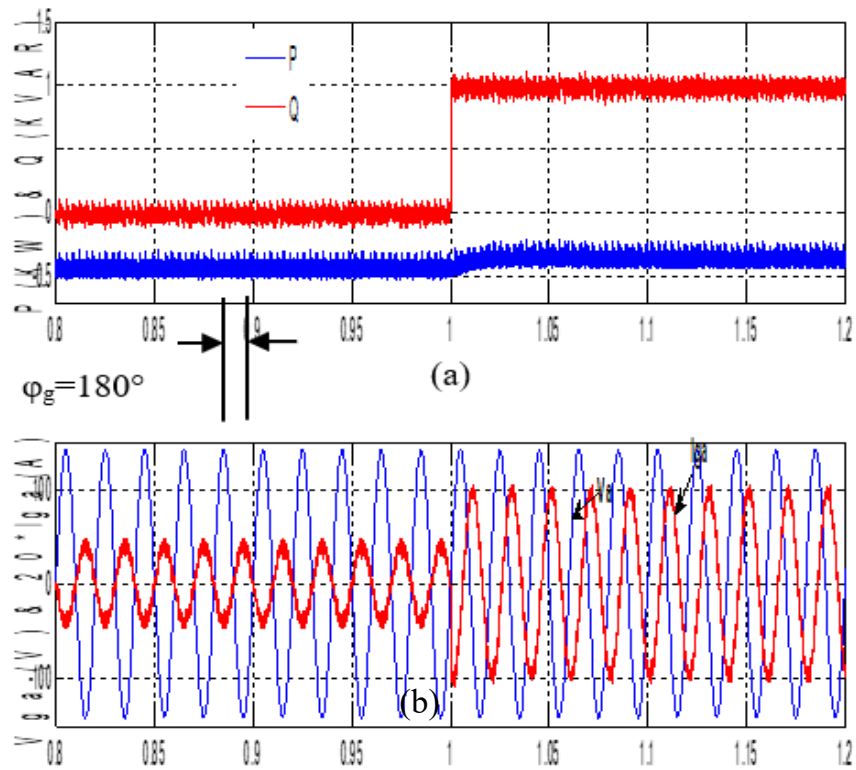

(b)

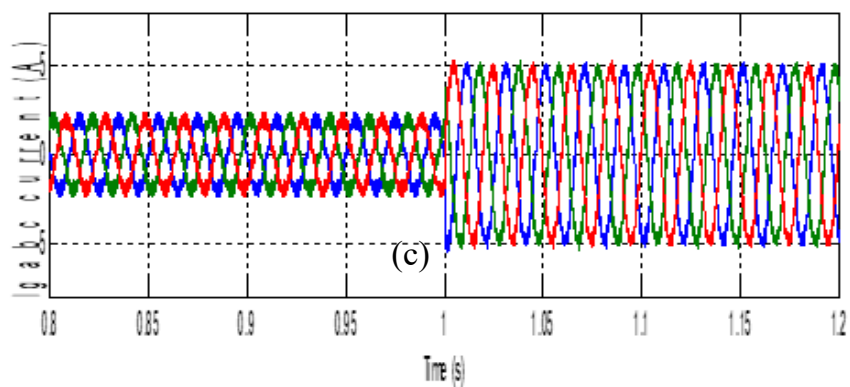

(c)

Figure 6. Tracking performance of the proposed control strategy: Active and reactive powers, voltage $v g a$ andcurrent iga, output currents

\section{DESCRIPTION OF LABORATORY SETUP}

The proposed control strategy was further validated by experiment using a laboratory setup bench, as shown in Figure 7.

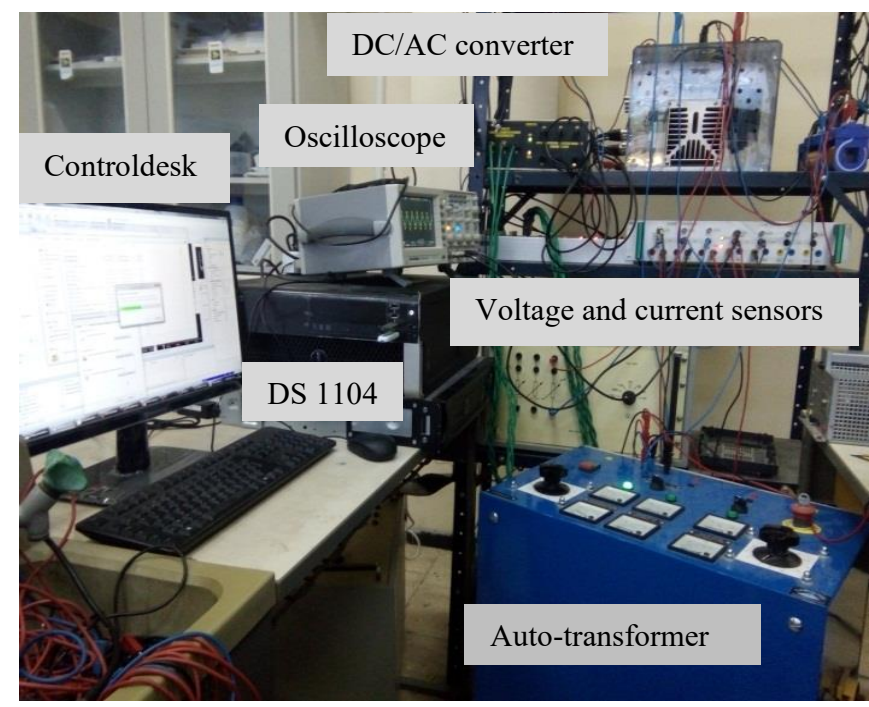

Figure 7. Experimental test bench
It consists of the following devices:

A three phase Semikron Electronic power converter composed of three IGBT modules, a dc power supplies source, and a three-phase isolated transformer, DC Link capacitor $1000 \mu \mathrm{F}$, a dSPACE card (model DS1104) with a PowerPC $604 \mathrm{e}$ at $400 \mathrm{MHz}$ and a floating-point digital signal processor (DSP) TMS320F240 with control panel, electronic card with voltage sensors (model LEM LV 25-P) and current sensors (model LEM LA 55-P) for monitoring the instantaneous values of the stator phase voltages and currents, voltage sensor (model LEM CV3-1000) for monitoring the instantaneous value of the dc-link voltage.

During the real-time operation of the control algorithm, the supervision and capturing of the important data can be done by the Control Desk software provided with the DSP board.

\section{PRACTICAL RESULTS ANALYSIS}

The performance of the proposed approach is investigated by the following tests.

The experimental results obtained are shown in Figure 8 and Figure 9. Figure 8 (a) to (d) demonstrate the steady-state relationship between the phase-a grid current and phase-a grid voltage with the changes in active power $P g$ and reactive power $Q g$ during three different regions in Figure 8 (a). In Figure 8 (d), $i_{a g}$ and $v_{a g}$ are in phase because $Q g$ equal to zero and grid power factor is unity.

The simulation and experimental results are identical in terms of dynamic response, decoupled control, and steady-state performance.

In Figure 9(a) and (b), a step-change in reactive powerfrom zero to negative value is applied, therefore the grid power factor changes from unity to leading. With negative $Q g$ value, the $i_{a g}$ leads the $v_{a g}$ waveform.

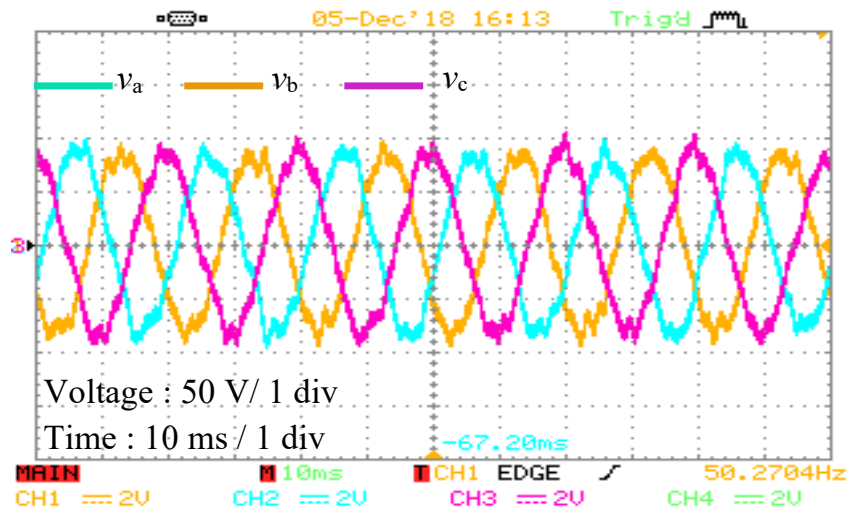

(a)

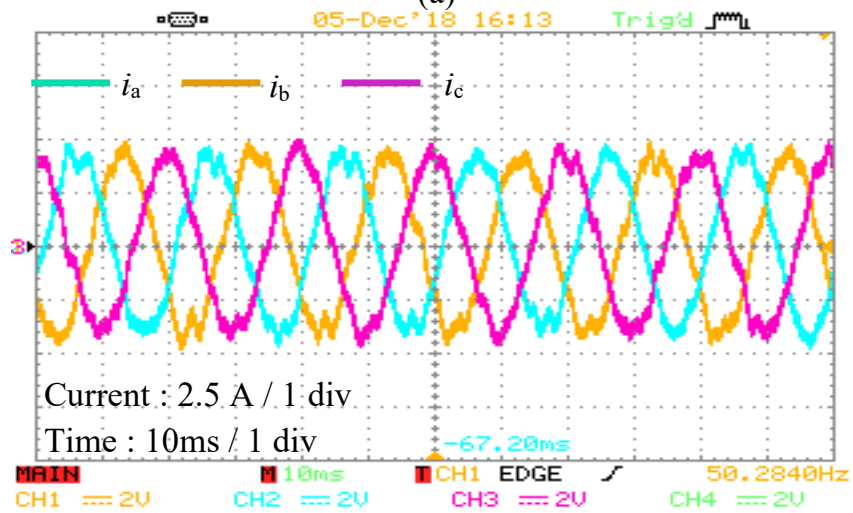

(b) 


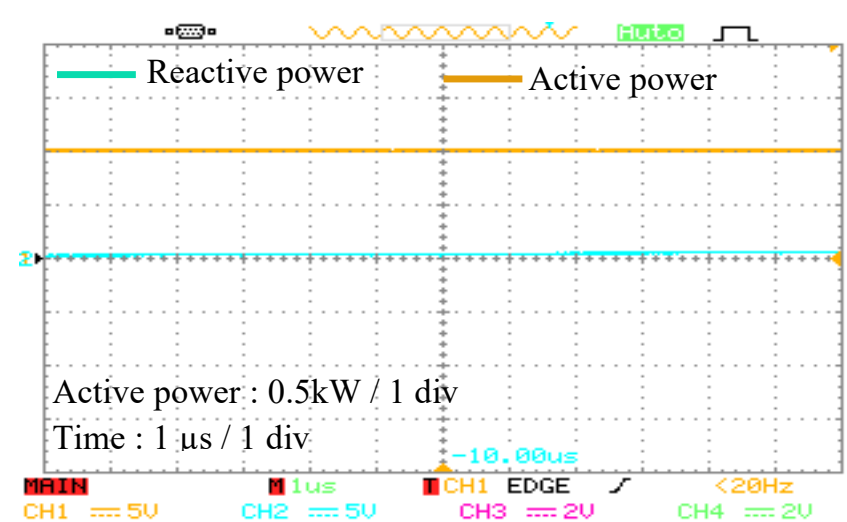

(c)

Figure 8. Experimental results: (a) three phase voltage, (b) three phase current, (c) active and reactive power

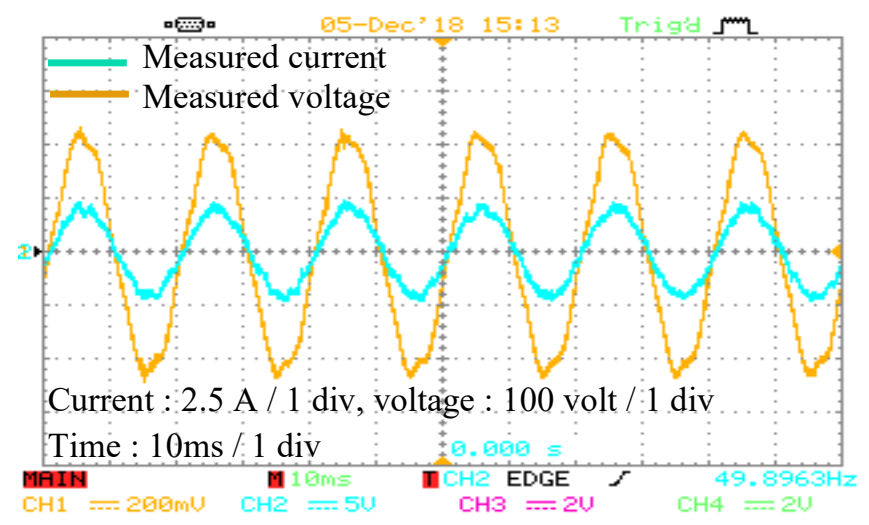

Figure 9. Experimental results: measured phase-a grid current iag and voltage vag

The reference tracking capability of control scheme is experimentally verified with step-changes $i_{d g}$ and $i_{q g}$ and the corresponding results are presented in Figure 9. The dq-axis reference and measured currents Figure 8 (d) are identical to the simulation results in terms of excellent reference tracking and fast dynamic response.

\section{CONCLUSIONS}

This work outlines the steps to be followed in simulating and practical investigation of a predictive control model algorithm for a two-level voltage source converter connected to a three-phase electrical power grid.

Four steps are used to design procedure of the proposed technique in terms of estimation of grid voltage angle, calculation and extrapolation of reference currents, prediction of future grid currents and selection of optimal switching signals through the cost function minimization.

The simulation results obtained are identical and similar to those obtained with the experimental tests. A fast-dynamic response is obtained for the grid currents in different operating conditions without the use of the conventional regulators PI and without the use of a modulation stage in the internal regulation loop. Despite the abrupt and extreme change in operating conditions, our experimental system remains stable and converges towards signature results.

The obtained results show the feasibility of the implementation of the proposed control technique that proved as a simple and powerful tool in controlling grid power with excellent performance indices.

\section{REFERENCES}

[1] Leffer, C., Hemphill, K., Sagg, A., Lee, R., Endsley, C., Almuharrami, O., Aluru, S., Yaramasu, V. (2017). Guidelines for dSPACE-based real-time implementation of predictive current control for grid-connected converters. IEEE Southern Power Electronics Conference (SPEC), Puerto Varas, Chile, pp. 1-8. https://doi.org/10.1109/SPEC.2017.8333574

[2] Gavilan, F., Caballero, D., Toledo, S., Maqueda, E., Gregor, R., Rodas, J., Rivera, M., Araujo-Vargas, I. (2016). Predictive power control strategy for a gridconnected 2L-VSI with fixed switching frequency. IEEE International Autumn Meeting on Power, Electronics and Computing (ROPEC 2016). Ixtapa, Mexico, pp. 1-6. https://doi.org/10.1109/ROPEC.2016.7830631

[3] Habib, M., Ladjici, A.A., Bollin, E. (2017). Finite set MPC control of two level inverter for PV/battery gridconnected system. Proceedings of the 6th International Conference on Systems and Control, Batna, Algeria, pp. 63-68. https://doi.org/10.1109/ICoSC.2017.7958673

[4] Yaichi, I., Semmah, A., Wira, P. (2019). Direct power control of a wind turbine based on doubly fed induction generator. European Journal of Electrical Engineering, 21(5): 457-464. https://doi.org/10.18280/ejee.210508

[5] Almaktoof, A.M., Raji, A,K., Kahn, M.T.E. (2014). Modeling and simulation of three-phase voltage source inverter using a model predictive current control. International Journal of Innovation, Management and Technology, $\quad 5(1)$ : https://doi.org/10.7763/IJIMT.2014.V5.477

[6] Parvez, M., Mekhilef, S., Tan, N., Akagi, H. (2014). Model predictive control of a bidirectional AC-DC converter for $\mathrm{V} 2 \mathrm{G}$ and $\mathrm{G} 2 \mathrm{~V}$ applications in electric vehicle battery charger. IEEE Transportation Electrification Conference and Expo (ITEC), Dearborn, USA, pp. 1-6. https://doi.org/10.1109/ITEC.2014.6861795

[7] Bayhan, S., Abu-Rub, H., Balog, R. (2016). Model predictive control of quasi-z-source four-leg inverter. IEEE Transaction on Inustrial Electronics, 63(7): 45064516. https://doi.org/10.1109/TIE.2016.2535981

[8] Geyer, T., Scoltock, J., Madawala, U. (2011). Model predictive direct power control for grid-connected converters. 37th Annual Conference of the IEEE Industrial Electronics Society, Melbourne, Australia, pp. 1438-1443. https://doi.org/10.1109/IECON.2011.6119519

[9] Miranda, H., Teodorescu, R., Rodriguez, P., Helle, L. (2009). Model predictive current control for high-power grid-connected converters with output LCL filter. 35th Annual Conference of IEEE Industrial Electronics, Porto, Portugal, pp. 633-638. https://doi.org/10.1109/IECON.2009.5414994

[10] Ahmadi, A., Ahmadifar, M., Ahmadi, S. (2015). Threephase inverter control by model predictive control. Research Journal of Recent Sciences, 4(1): 81-86.

[11] Monteiro, V., Ferreira, J.C., Meléndez, A.A.N., Afonso, J.L. (2016). Model predictive control applied to an improved five-level bidirectional converter. IEEE Transactions on Indutrial Electronics, 63(9): 5879-5890. 
https://doi.org/10.1109/TIE.2016.2558141

[12] Islam, K., Abdelrahem, M., Kennel, R. (2016). Efficient finite control set-model predictive control for gridconnected photovoltaic inverters. IEEE International Symposium on Industrial Electronics, Banja Luka, Bosnia and Herzegovina, pp. 1-6. https://doi.org/10.1109/INDEL.2016.7797793

[13] Gui, Y., Kim, C., Chung, C.,Guerrero, J.M., Guan, Y., Vasquez, J.C. (2018). Improved direct power control for grid-connected voltage source converters. Transactions on Industrial Electronics, 65(10): 8041-8051. https://doi.org/10.1109/TIE.2018.2801835

\section{NOMENCLATURE}

$v_{d g}, v_{q g}$

$v_{i d}, v_{i q}$

$i_{d g}, i_{q g}$

$R g$

$L_{d g}, L_{q g}$

$\omega_{g}$

$v_{d c}$

$v_{d c}{ }^{*}$

$i_{d c}$

C

$R_{s}$

$P_{g}$

$Q_{g}$

$S_{a i}$

$T_{s}$

$f$

$k$

$k+1$

$k-1$
Grid peak voltages in dq-frame[V]

Voltage inverter d, q components [V]

Grid peak currents in dq-frame[A]

Input filter resistance[ $\Omega]$

Input filter inductance $\mathrm{d}, \mathrm{q}$ components [mH]

Grid angular frequency [rad/s]

Dc bus voltage[V]

Reference Dc bus voltage[V]

Dc bus current $[\mathrm{A}]$

DC link capacitor[mF]

Load resistance $[\Omega]$

Active power grid [KW]

Reactive power grid [KVAR]

Switching state

Sampling time $[\mu \mathrm{s}]$

Grid frequency $[\mathrm{Hz}]$

Present sampling instant in discrete-time frame

Future sampling instant in discrete-time frame

Past sampling instant in discrete-time frame

\section{Greek symbols}

$\varphi \mathrm{g}$

Grid power factor angle (angle between grid voltage and current)

Subscripts

$\begin{array}{ll}\text { 2L } & \text { Two Level (converter) } \\ \text { AC } & \text { Alternatif Current } \\ \text { DC } & \text { Direct Current } \\ \text { DSP } & \text { Digital Signal Processor } \\ \text { DTC } & \text { Direct Torque Control } \\ \text { GCC } & \\ \text { IGBT } & \text { Insulated Gate Bipolar Transistor } \\ \text { MPC } & \text { Model Predictive Control } \\ \text { MPDPC } & \text { Model Predictive Direct Power Control } \\ \text { NPC } & \text { Neutral Point Clamped } \\ \text { OPP } & \text { Optimized Pulse Patterns } \\ \text { PPC } & \text { Predictive Power Control } \\ \text { PWM } & \text { Pulse Width Modulation } \\ \text { TDD } & \text { Total Demand Distorion } \\ \text { THD } & \text { Total Harmonic Distorsion } \\ \text { VF } & \text { Virtual Flux } \\ \text { VSC } & \text { Voltage Source Converter } \\ \text { VSI } & \text { Voltage Source Inverter }\end{array}$

\section{APPENDIX}

Table 1. Rated parameters for grid connected converter

\begin{tabular}{cc}
\hline Components & Rating values \\
\hline Power rating & $P=1.5 \mathrm{~kW}$ \\
\hline Three phase grid voltage & $V_{s}=220 \mathrm{~V}$ \\
\hline Grid frequency & $f=50 \mathrm{~Hz}$ \\
\hline DC bus voltage & $V_{d c}=200 \mathrm{~V}$ \\
\hline Input filter resistance & $R_{g}=2.5 \Omega$ \\
\hline Input filter inductance & $L_{g}=9 \mathrm{mH}$ \\
\hline Sampling time & $T_{s}=50 \mu \mathrm{s}$ \\
\hline Load resistance & $R_{s}=100 \Omega$ \\
\hline DC link capacitor & $C=1100 \mu \mathrm{F}$ \\
\hline
\end{tabular}

